\title{
Correction to: Enhanced Growth of Pilin-Deficient Geobacter sulfurreducens Mutants in Carbon Poor and Electron Donor Limiting Conditions
}

\author{
Lucie Semenec $^{1} \cdot$ Ismael A. Vergara ${ }^{2} \cdot$ Andrew E. Laloo $^{3}$ - Elizabeth R. Mathews ${ }^{1} \cdot$ Philip L. Bond ${ }^{3} \cdot$ \\ Ashley E. Franks ${ }^{1,4}$ (1)
}

Published online: 30 March 2019

(C) Springer Science+Business Media, LLC, part of Springer Nature 2019

\section{Correction to: Microb Ecol \\ https://doi.org/10.1007/s00248-019-01316-8}

The published version of this article contained an old version of Fig. 2. Below is attached the updated version of Fig. 2. This update does not change the results and conclusions originally reported as the published article refers to this updated version of Fig. 2.

The online version of the original article can be found at https://doi.org/ $10.1007 / \mathrm{s} 00248-019-01316-8$

Ashley E. Franks

A.Franks@latrobe.edu.au

1 Department of Physiology, Anatomy and Microbiology, La Trobe University, Melbourne, Victoria, Australia

2 Bioinformatics and Cancer Genomics, Research Division, Peter MacCallum Cancer Centre, Melbourne, Victoria, Australia

3 Advanced Water Management Centre, The University of Queensland, Brisbane, Queensland, Australia

4 Centre for Future Landscapes, La Trobe University, Melbourne, Australia 


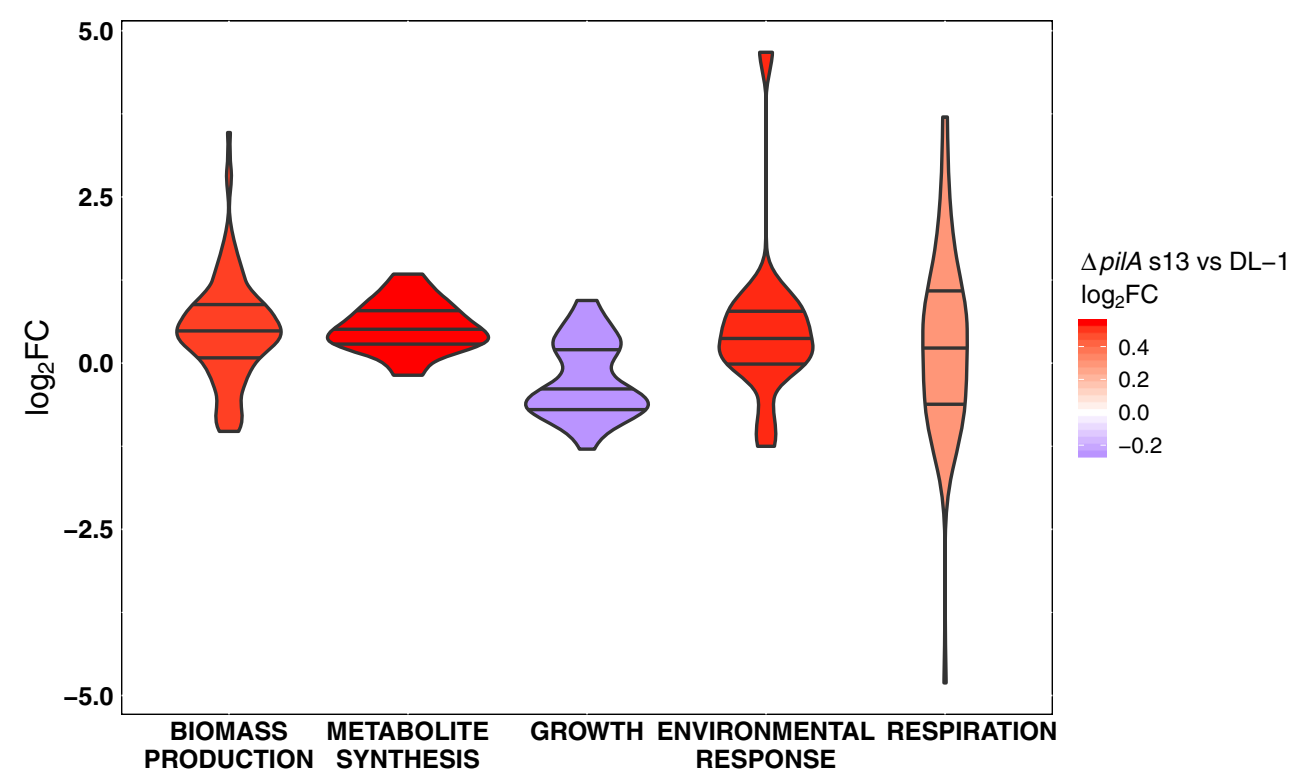

Fig. 2 Violin plot representing difference in protein abundances of the $\triangle$ pilA adapted (s13) grown with formate and fumarate versus wild-type DL-1 in acetate and fumarate. Each violin represents the median $\log 2$ fold change difference of proteins within a functional pathway group in $\Delta$ pilA

adapted (s13) mutants versus DL-1. Scales within each violin indicate $1^{\text {st }}$ quartile, median and $3^{\text {rd }}$ quartile values. The spread of the violin represents the distribution of the $\log _{2} \mathrm{FC}$ of each protein comparison 